\title{
Evaluation and Characterization of a Durable Composite Phase Thermal Barrier Coating in Solid Particle Erosion and Burner Rig Tests
}

\author{
Xinqing $\mathrm{Ma}^{1} \cdot$ Kristina Rivellini $^{1} \cdot$ Peter Ruggiero $^{1} \cdot$ George Wildridge $^{2}$
}

Submitted: 22 June 2020/in revised form: 4 August 2020/ Accepted: 11 September 2020/Published online: 9 October 2020

(C) ASM International 2020

\begin{abstract}
A new concept of composite phase ceramic had been proposed for the topcoat of a durable thermal barrier coating (TBC) system which is one of the critical technologies for advanced turbine engines. The composite phase TBCs showed promising performance related benefits over conventional single phase TBCs, including durability, material affordability, thermal stability and low thermal conductivity. The present work is to continue the effort to exploring the TBC behaviors of erosive wear by solid particle erosion test and thermal cyclic shock by special burner rig test. In the erosion test, the investigation was focused on the most important characteristics of erosion test results using different characterization methods, including the variations of erosion damages with impingement angle and finally the effect of high temperature sintering. In the burner rig test, the TBC was exposed to a rapidly thermal cycling condition introduced by a high heat flux and high-velocity combustion torch. The TBC damages and failure modes were identified and explained in terms of microstructural observation and mechanism discussion. The composite phase $\mathrm{c}+\mathrm{t}^{\prime}$ TBC demonstrated improved erosion resistance relative to a $\mathrm{Gd}_{2} \mathrm{Zr}_{2} \mathrm{O}_{7} \mathrm{TBC}$
\end{abstract}

This article is an invited paper selected from abstracts submitted for the 2020 International Thermal Spray Conference, ITSC2020 that was to be held from June 10-12, 2020, in Vienna, Austria. The conference was cancelled due to the coronavirus (COVID-19) pandemic. The paper has been expanded from the planned presentation.

Xinqing Ma

chin.ma@cwst.com

1 Surface Technologies Division, Curtiss-Wright Corporation, East Windsor, CT, USA

2 IMR Test Labs, Curtiss-Wright Corporation, Lansing, NY, USA and equivalent thermal shock resistance to a conventional 8YSZ TBC.

Keywords air plasma spray · burner rig test · coating characterization $\cdot$ erosion test $\cdot$ thermal barrier coating

\section{Introduction}

Thermal barrier coatings (TBCs) have been widely applied to the surfaces of components in various high temperature environments, not limited to the critical turbine engine parts such as combustion liners, fuel nozzles, blades and vanes in turbine hot sections (Ref 1-3). Advanced TBCs will allow higher inlet temperatures for improved engine efficiency and extended lifetime. Therefore, it is necessary to develop optimal materials and offer the best possible solutions to meet the demands for advanced TBCs (Ref 46). In authors' previous work, a composite phase ceramic was designed, optimized and tested for the topcoat in a $\mathrm{TBC}$, and the test results of oxidation, thermal shock and thermal stability are very promising in comparison to a regular 8YSZ TBC and also a zirconate-based TBC (Ref 7). Additionally, the composite phase TBC demonstrated low thermal conductivity as theoretical predicted and experimental measured as $0.6-0.9 \mathrm{~W} / \mathrm{m} \cdot \mathrm{K}$ in the range of $1000-1200{ }^{\circ} \mathrm{C}(\operatorname{Ref} 7,8)$.

In typical gas turbine operating conditions, TBCs' degradation, damage or even failure can cause serious safety risk and performance loss. The impact of those factors such as thermal shock resistance and particle erosion resistance should be carefully evaluated for TBCs' performance, reliability and durability. To design a reliable $\mathrm{TBC}$, in practice, burner rig test is widely used to determine the thermal cycling resistance of a TBC under rapidly 
heating and cooling condition (Ref 9-11). However, a typical lab setup of burner rig test can only simulate temperature cycling using a flame torch without offering sufficiently high velocity of the hot gas stream as generated in an actual engine. In such a simplified setup, void of the strong hot gas impact, washing and or erosion, the behavior of damage, delamination or spallation of the TBC tested will deviate from the true behavior and not represent the failure mode in actual TBC engine operating condition.

Gas turbine engines used in commercial and military aircrafts as well as power generation systems may ingest erosive particles from polluted atmosphere and incomplete combustion fuel soots at ground low altitude, storm dust clouds and even volcanic ashes at high altitude. Other potential source for particle impact and erosion include spallation of buildup stuff carbon soots, damaged coatings or chipped components inside the engines. Generally, there are two classes of particle impact damages: (1) Class 1: Foreign object damage (FOD). High-velocity impacts due to bird strike, tyre debris and other foreign objects with relative large size and mass can cause severe damages to components and may result in critical safety issues. (2) Class 2: Solid particle erosion (SPE). Particles with micron sizes impact on surfaces of components or coatings will cause microscale deterioration such as erosion, fracture, cracking, deformation and/or hardening. The erosion natured impact damages will lead to localized removal of coating materials and eventually end with coating loss and functional failure. As indicated in Fig. 1, erosive wear behavior of a material can be identified based on the mode 1 for ductile materials like metals and alloys, and the model 2 for brittle materials like ceramics (Ref 12). The combined model 3 is suitable for composite materials such as HVOF

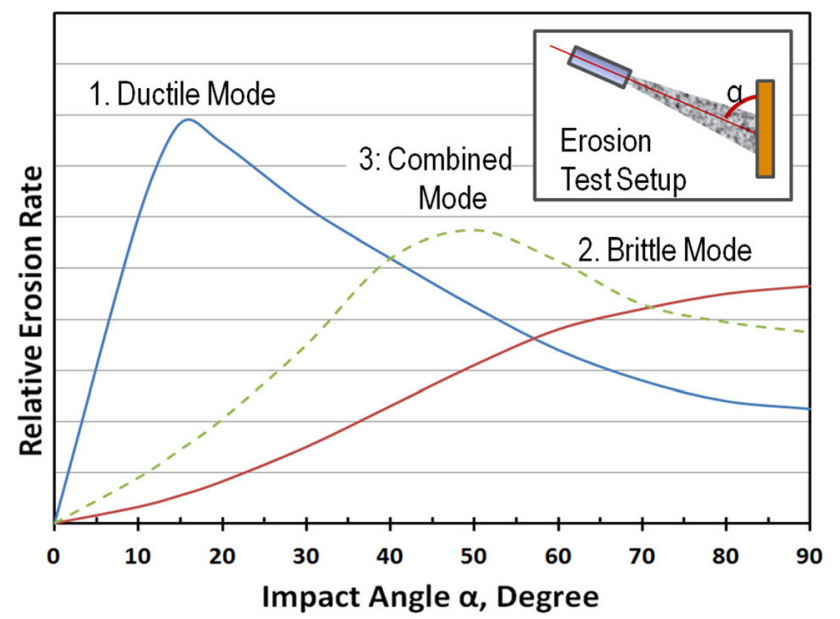

Fig. 1 Typical behavior of solid particle erosive wear for the materials with different natures and properties (Ref 12, 13). Mode 1: Ductile material; Mode 2: Brittle material; Mode 3: Combined mode of mode 1 and mode 2, a case of composite material
WC-CoCr coating (Ref 13). It also is shown the impact angle is a key factor to affect erosion rate and failure mode for those materials with different chemical, microstructure and property. The erosion behaviors of thermal barrier coatings had been investigated by some researchers. Ramachandran et al. investigated the erosive wear resistance of YSZ and lanthanum zirconate (LZO) coatings with respect to different porosity, velocity of erodents and impact angles (Ref 14). Further, Mahade et al. studied the erosion performance of gadolinium zirconate $(\mathrm{GZO})$ and its composite TBCs produced by suspension plasma spray (SPS) (Ref 15-17), and found that material composition and microstructural design had major impact on their erosion behaviors. In most of the cases, the increase in YSZ content and coating density for those TBCs showed better erosion resistance, which is consistent with our finding in previous study related (Ref 7). Our current research will focus on erosion behavior and mechanism of composite phase TBCs.

Due to the importance of thermal shock resistance and erosion resistance for the development of the advanced composite phase $\mathrm{TBC}$, the present work as continuing effort had focused on exploring and characterizing the behavior of the TBC in solid particle erosion and burner rig tests. Erosion test was focused on the characteristics of erosion behavior, including the changes of erosion damages with impingement angle and with the effect of high temperature sintering. The erosion mechanisms were discussed based on the topographic analyses of the eroded surfaces. The burner rig test was conducted by adopting a high heat flux and high-velocity combustion torch to generate a rapidly thermal cycling and strong gas impact condition. The TBC damages and failure modes were identified and explained in terms of experimental observation, data analysis and mechanism discussion.

\section{Experimental}

\section{Preparation of Coating Specimens}

TBC specimens were produced by Curtiss-Wright Surface Technologies ("CWST") using a F4 plasma torch (Metco, Westbury, NY) for ceramic topcoats and a Jet Kote-3000 HVOF torch (Stellite, Goshen, IN) for a metallic CoNiCrAlY bond coat (CO-210-24, Praxair) onto Haynes 188 substrates. A rough CoNiCrAlY flash layer over the dense alloy bond coat was applied by HVOF process to improve the interface bonding between the bond coat and the topcoat. An interlayer of $t^{\prime}$ phase zirconia was deposited over the bond coat prior to applying the composite phase topcoat. For comparison, regular $8 \mathrm{YSZ}$ TBC and $\mathrm{Gd}_{2} \mathrm{Zr}_{2} \mathrm{O}_{7}$ TBC also were prepared. Some of the TBCs were aged at 
$1300{ }^{\circ} \mathrm{C}$ for $25 \mathrm{~h}$ at a heating rate of about $10{ }^{\circ} \mathrm{C} / \mathrm{min}$ using a box furnace (ST-1700, Sentro Tech Corp, Berea, OH). The TBC specimens have a typical porosity of $13-15 \%$ and a topcoat thickness of about $200 \mu \mathrm{m}$ for burner rig test and $800 \mu \mathrm{m}$ for erosion test.

All the test specimens are listed in Table 1. The optimal spray parameters were employed for fabricating the composite phase TBC, and also more details about thermal spray parameters were disclosed in Table 2.

\section{Solid Particle Erosion Test}

Erosion tests by solid particle impingement were performed using a modified test rig (Curtiss-Wright Surface Technologies, CT) similar to that described in ASTM G76 standard. Instead of a fixed impingement angle of $90^{\circ}$, the angle was taken as 20, 45, 60, 75 and $90^{\circ}$ while maintaining the same standoff distance at $100 \mathrm{~mm}$. Erodent particles of irregular shaped alumina has average grit size of approximately $50 \mu \mathrm{m}$. The thickness and weight of the specimens were measured and recorded before and after the erosion tests. Thickness loss was determined by the maximum eroded depth in the TBCs after erosion tests. The usage of alumina grit and erosion test duration time were recorded during each test run. The erosion rates of the specimens were determined by three methods. Method 1: Maximum depth of coating removal per erosion time, $\mu \mathrm{m} /$ s. Method 2: Mass loss of coating per erosion time, $\mathrm{g} / \mathrm{s}$. Method 3: Mass loss of coating per erodent usage, g/g. The surfaces of eroded specimens were examined by optical microscope and SEM closely.

\section{Burner Rig Test}

An internal procedure for high-velocity burner rig test had been developed and performed mainly for the purpose of simulating TBC behavior in a close condition for engine operation under high heat flux and high gas velocity. As illustrated in Fig. 2, a high energy combustion torch (Metco 6P-II, Westbury, NY) was employed to generate sufficient heat input to a homogeneous surface temperature at the maximum $1200{ }^{\circ} \mathrm{C}$ and a high-velocity gas impact on the TBC surfaces. The torch used acetylene fuel and oxygen and generated a uniform heating zone on the surface of $25 \mathrm{~mm}$-diameter disk specimens, as well as a high-velocity gas stream via an accelerating nozzle. The test samples were mounted on a cylindrical sample holder which attached to an index rotation turntable. The temperatures on the front and rear surfaces of the TBC samples were continuously monitored by two digital pyrometers (Extech, accuracy: $\left.\pm\left(3 \% \mathrm{rdg}+2{ }^{\circ} \mathrm{C}\right)\right)$ which were aligned to the test sample surfaces with propriate focus distances. As shown in Fig. 2, a thermal cycle comprises of 30-second heating to the peak temperature $1200{ }^{\circ} \mathrm{C}$ and 60 -second cooling to below $100{ }^{\circ} \mathrm{C}$ when the torch was moved to the adjacent sample and two air jets were turned on to cool the heated sample from both front and rear sides. The maximum thermal gradient between the front surface and rear surface was measured about $350{ }^{\circ} \mathrm{C}$ when the heating torch just was moved toward the adjacent sample and the heated sample started to cool down. The tested TBC samples were examined on the coating surfaces at 1000, 1500 and 2000 cycles, respectively. The percentage of coating spallation area was calculated from image analysis results for each sample as detailed in previous work (Ref 7). As a rule of thumb, the spallation percentage more than $30 \%$ is considered as coating failure.

\section{Surface Topograph}

$3 \mathrm{D}$ topographs of the eroded coating surfaces and 2D surface profiles were measured with advanced digital microscope (Keyence VHX, Japan). The 3D topographic images were taken by scanning selected eroded areas on the TBC surfaces. The 2D surface profiles were measured on the $X$-direction along the impinging direction and the $Y$ direction laterally across the erosion scar as shown in Fig. 3. The surface profile in $Y$-direction was used to determine the maximum depth of coating removal and to calculate erosion rate.
Table 1 List of TBCs used for erosion test and burner rig test

\begin{tabular}{ll}
\hline Sample no. & \multicolumn{1}{c}{ Description of specimens } \\
\hline 1. Erosion test specimens & \\
E-1A & $\mathrm{c}+\mathrm{t}^{\prime}$ composite phase $\mathrm{TBC}$, as-sprayed \\
E-1H & $\mathrm{c}+\mathrm{t}^{\prime}$ composite phase $\mathrm{TBC}$, aged at $1300^{\circ} \mathrm{C} / 25 \mathrm{~h}$ \\
E-2A & $\mathrm{Gd}_{2} \mathrm{Zr}_{2} \mathrm{O}_{7} \mathrm{TBC}$, as-sprayed \\
E-2H & $\mathrm{Gd}_{2} \mathrm{Zr}_{2} \mathrm{O}_{7} \mathrm{TBC}$, aged at $1300^{\circ} \mathrm{C} / 25 \mathrm{~h}$ \\
2. Burner rig test specimens & \\
B-1A & $\mathrm{c}+\mathrm{t}^{\prime}$ composite phase $\mathrm{TBC}$, as-sprayed \\
B-2A & $\mathrm{t}^{\prime} 8 \mathrm{YSZ} \mathrm{TBC}$, as-sprayed \\
\hline
\end{tabular}


Table 2 Thermal spray main parameters used for the TBC specimens

\begin{tabular}{ll}
\hline Sample no. & \multicolumn{1}{c}{ Description of specimens } \\
\hline Thermal spray main parameters using a F4 plasma gun \\
B-2A & Ar flow: $90, \mathrm{H}_{2}: 7.5$, current: $600 \mathrm{~A}$, voltage: $50 \mathrm{~V}$, \\
& S.D.: $150 \mathrm{~mm}$, feed rate: $60 \mathrm{~g} / \mathrm{min}$ \\
E-1A & Ar flow: $120, \mathrm{H}_{2}: 10$, current: $500 \mathrm{~A}$, voltage: $60 \mathrm{~V}$, \\
& S.D.: $100 \mathrm{~mm}$, feed rate: $50 \mathrm{~g} / \mathrm{min}$ \\
E-2A & Ar flow: $80, \mathrm{H}_{2}: 10$, current: $500 \mathrm{~A}$, voltage: $60 \mathrm{~V}$, \\
& S.D.: $100 \mathrm{~mm}$, feed rate: $50 \mathrm{~g} / \mathrm{min}$ \\
\hline
\end{tabular}

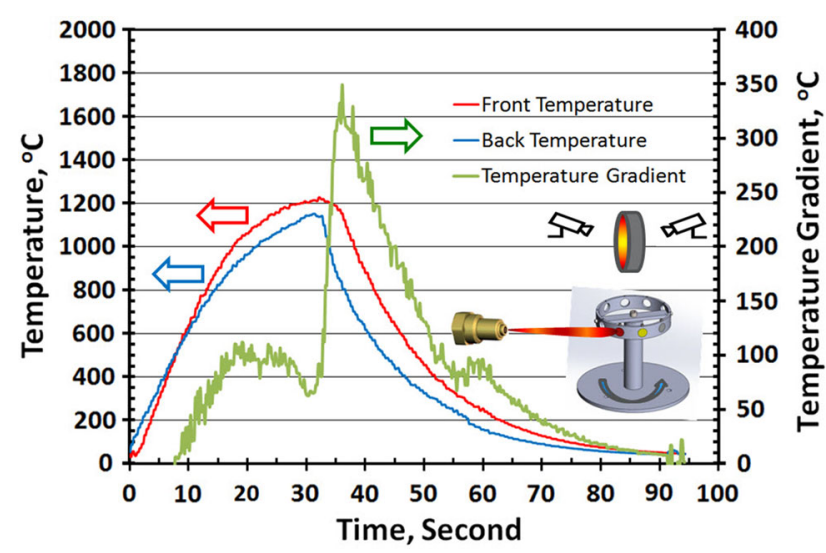

Fig. 2 Schematic of burner rig test setup using a high heat flux and high-velocity torch

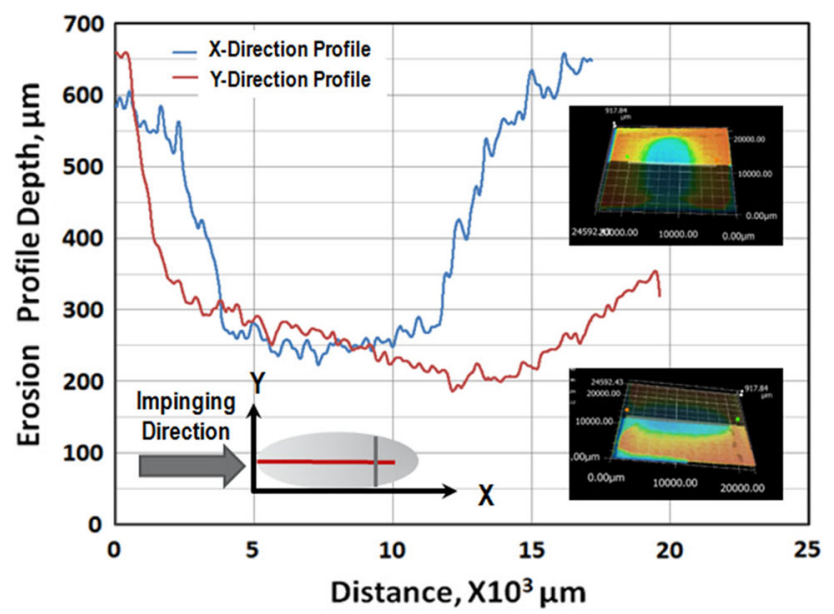

Fig. 3 Typical 3D topographs of erosion scars and 2D profiles in $X$ and $Y$-directions

\section{Coating Characterization}

The microstructures and some material properties of the TBC samples had been evaluated and characterized using different technologies in as-sprayed and tested coating conditions. The coating microstructures on cross sections and eroded surfaces were examined by optical microscope and SEM. Coating porosity was determined by image analysis method. The fracture toughness $K_{\text {Ic }}$ of the TBCs was measured by Vickers micro-indentation method under a load of $1000 \mathrm{~g}$. Then, the fracture toughness was calculated mainly from Palmqvist-type cracking length (Ref 1820). The cracking lengths were measured from the optical images of the indentations on the TBC cross sections. Further, the detailed erosion scars and surface features for the tested TBCs were closely observed by SEM imaging method.

\section{Results and Discussion}

\section{TBC Microstructure}

The TBC specimens listed in Table 1 were examined on their cross sections, and selectively are given in Fig. 4. In general, the TBCs have a typical coating microstructures fabricated by APS process, with well melted splats and good adhesive bonding to the substrates. The SEM image in Fig. 4(b) provides more details of the microstructure features in the topcoat of composite phase TBC \#E-1A. The features include predominant dense coating areas due to fully melting of feedstock, porosity cluster areas due to partially melting of agglomerated feedstock, distinct splat boundaries and scattered pores at splat boundaries. This multiple-mode porosity structure is beneficial for lowering thermal conductivity of the TBC and enhancing strain tolerance. The sintering at $1300{ }^{\circ} \mathrm{C}$ for approximate $100 \mathrm{~h}$ had proven that the sintering affected the TBC porosity mostly on the splat boundaries and associated porosity (Ref 7). 8YSZ-TBC and zirconate TBC has a typical singlemode porosity structure. The coatings had been prepared with optimized spray parameters for good material melting and controlled coating porosity $13-15 \%$.

\section{Evaluation of Erosion Test}

\section{Morphology and Surface Profile}

The TBC specimens after the erosion tests were inspected on the eroded surfaces with an optical microscope and a digital microscope, and some results are given in Fig. 5. In Fig. 5(a), it shows the dependence of the geometry and size 

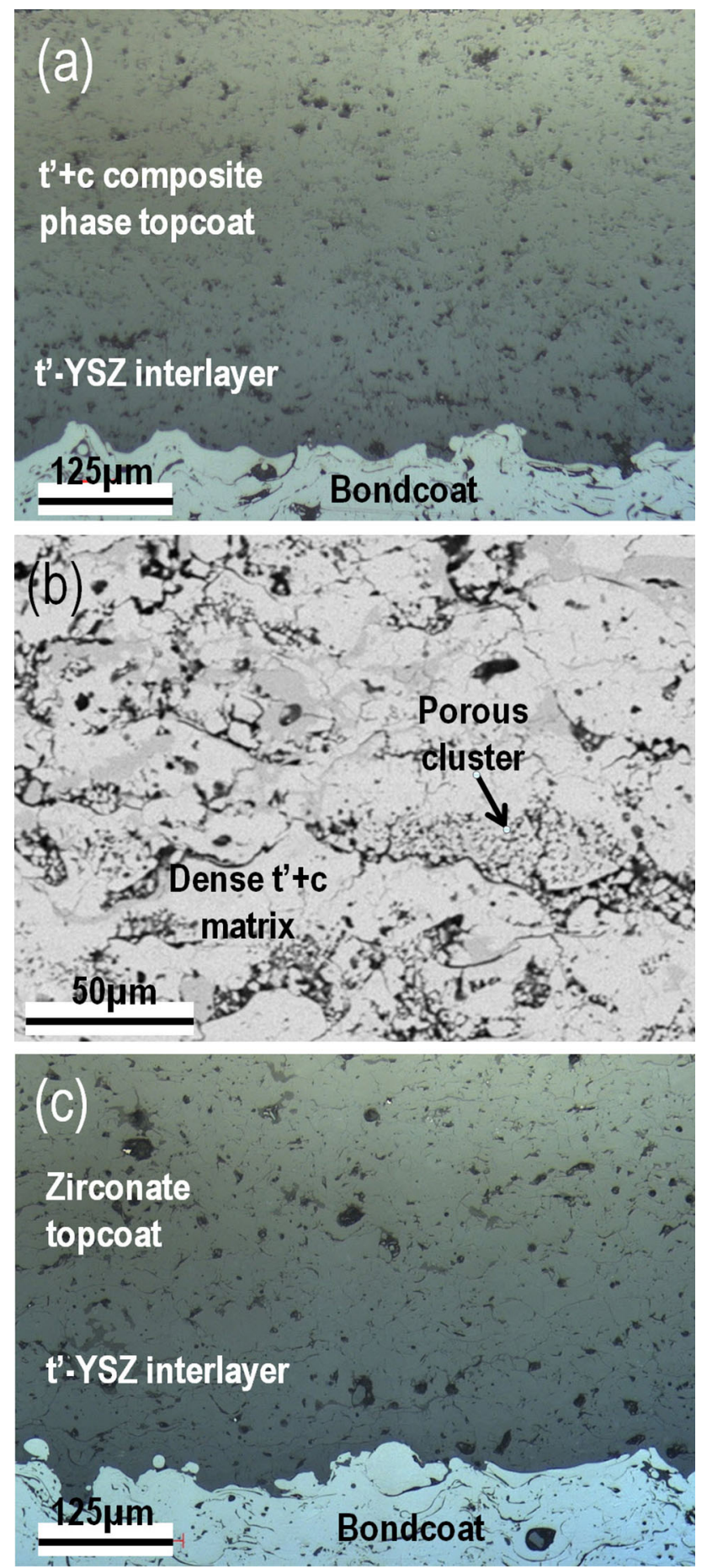

Fig. 4 Microstructures of (a), (b) composite phase TBC (\#E-1A) and (c) $\mathrm{Gd}_{2} \mathrm{Zr}_{2} \mathrm{O}_{7}$ zirconate TBC (\#E-2A)

of erosion scars on impingement angles from 20 to $90^{\circ}$. One observation from the macro-photographs of the eroded scars, indicates that the width of the distinct erosion scars increase with increased impact angles. The geometry of the eroded scars changes from elongated ellipse shape to near round shape. The Fig. 5(b) and (c) clearly show two or
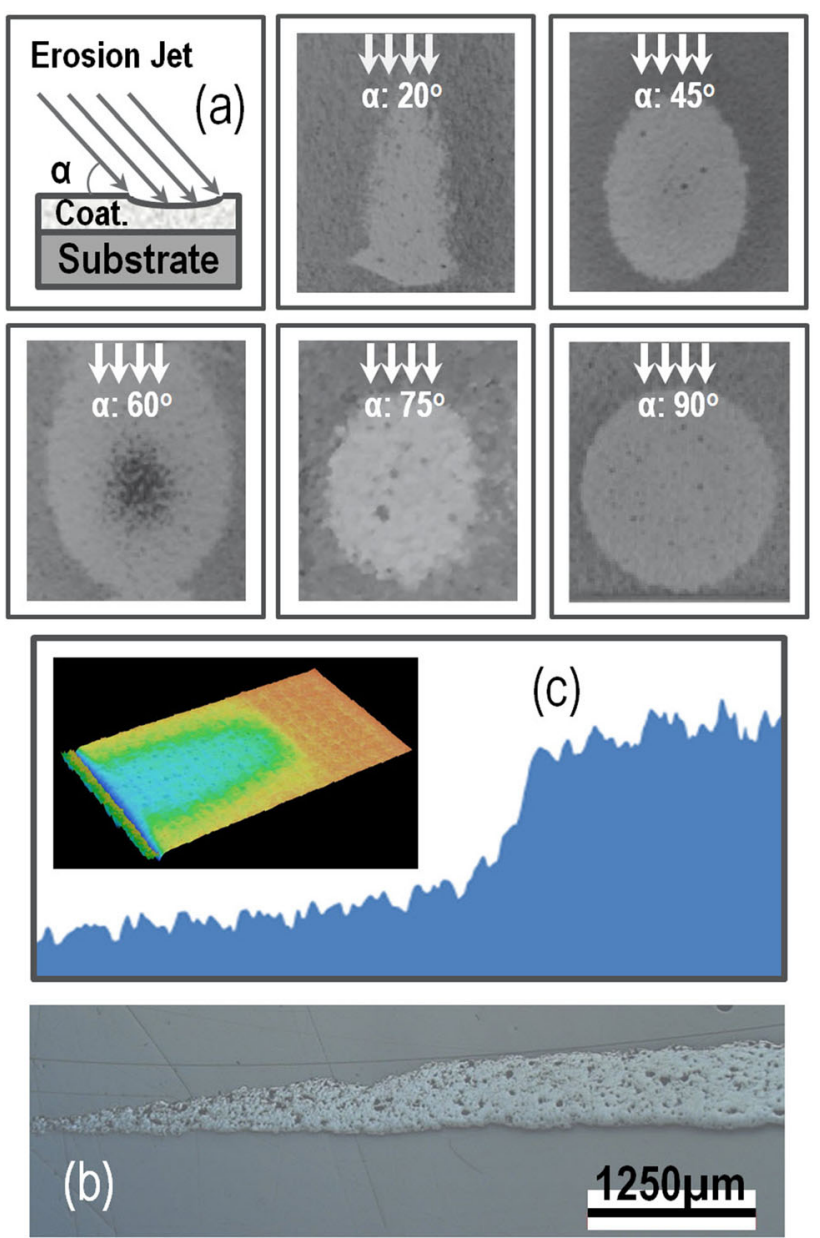

Fig. 5 Photographs of (a) erosion scars on the TBCs at different impinging angles, (b) cross section of tested sample \#E-1A at angle $20^{\circ}, *$ (c) thickness profile in $Y$-direction and 3D map image for the sample in (b)

three erosion regions: (1) Zone 1: At the center of the scar where the maximum erosion takes place; (2) Zone 2: Transitional area between the center and outer edge region where medium amount of erosion takes place; and (3) Zone 3: Outer edge region, where lesser amount of erosion takes place. The maximum depth of erosion always was measured in the Zone 1 along $Y$-direction as shown in Fig. 3 . The uneven erosion in the three zones can be explained by the fact that the flux density and velocity of the grit particles is not evenly distributed along the radial center of the air stream, as observed by other related studies. Because of the nature of uneven erosion, it is quite sensitive to characterize coating erosion rate by measuring the maximum thickness loss using a measurement tool such as micrometer. 3D digital microscope was used as a useful and necessary tool for precise measurement of surface profile to determine the maximum depth after the erosion test. 


\section{Characterization of Erosion Rate}

The erosion rates for the TBC specimens were determined using three methods. The results of the erosion rates measured by method 1 are shown in Fig. 6(a), and the results from three methods are compared in Fig. 6(b). The results can be summarized and interpreted as follows:

- Among of all the specimens, the group of composite phase TBCs (\#E-1A, \#E-1H) has much lower erosion rates than the group of zirconate TBCs (\#E-2A, \#E$2 \mathrm{H})$.

- The sintering treatment at $1300{ }^{\circ} \mathrm{C}$ is more influential for the group $1(\# \mathrm{E}-1 \mathrm{~A}, \# \mathrm{E}-1 \mathrm{H})$ to reduce erosion rate relative to the group 2 (\#E-2A, \#E-2H). In contrast, the aging of the group 2 has no much effect on erosion rate.

- It is clearly indicated the significant effect of impinging angle on the erosion behaviors of the TBCs. All the samples are more pronounced to erosion at higher angle
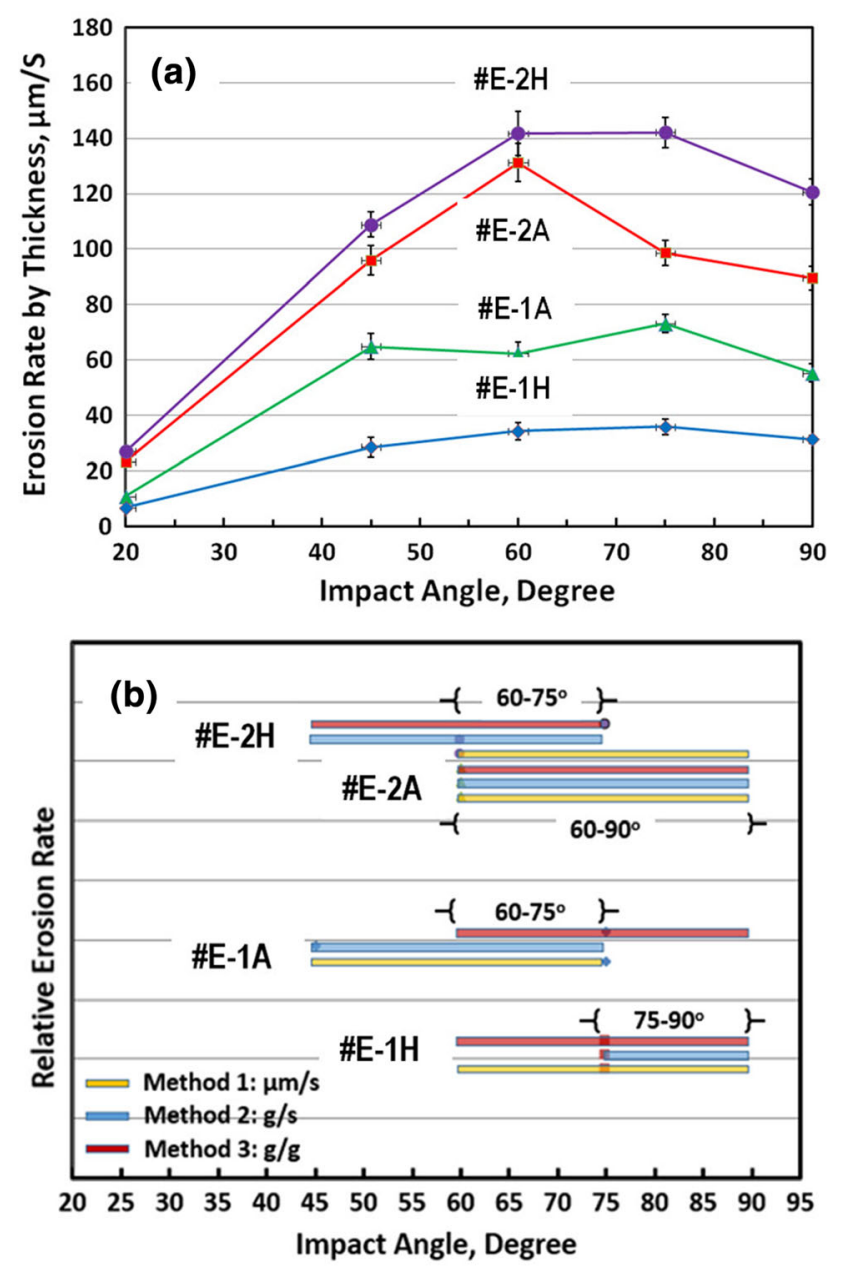

Fig. 6 Plot of erosion rate as a function of impingement angle. (a) Erosion rate measured by the maximum thickness loss per erosion time, $\mu \mathrm{m} / \mathrm{s}$; (b) comparison of erosion rates characterized by three methods more than $60^{\circ}$. As cited in Fig. 1, a combined mode associated with both rough and brittle material nature seems to be suitable for describing the erosion behaviors of both the groups.

- The comparison on the erosion rates (Fig. 6b) derived from three methods indicates that there are "common" overlapping regions for the high erosion rates as function of impact angle. For example, the as-sprayed $c+t^{\prime}$ TBC \#E-1A shows the overlapping region on the high erosion rates from three methods in the range of $60-75^{\circ}$, but the aged $\mathrm{c}+\mathrm{t}^{\prime}$ TBC \#E-1H moves the region toward higher angle at $75-90^{\circ}$. The shift in erosion region may imply the main cause of the erosion losses is varied after the sintering treatment. Therefore, the common regions for each type of the TBCs can present the dominant erosion behavior as a function of impact angle.

The characterization methods for erosion rate can be considered and selected based on different situations. Method 1 -rate at $\mu \mathrm{m} / \mathrm{s}$, is widely used for determining the worse erosion rate when the coating loss in thickness is considered critical for coating damage or failure in a localized area. When erosion happens at a relative low impinging angle, the method 1 is typically applied. It is often used for erosivity \# calculation $(\mathrm{s} / \mu \mathrm{m})$. To determine the maximum thickness loss in the eroded coating will require good technology for reliable measurement. Method 2-rate at $\mathrm{g} / \mathrm{s}$, can give an average of accumulated mass loss over a test period. It provides an overall erosion resistance of the coating material with relatively reliable result, and is suitable for monitoring erosion progress and comparing the erosion behavior of different samples. Method 3-rate at g/g (i.e., coating mass loss/grit mass), includes the factor of grit flux into the erosion result. In some case, the test condition may not be constant, such as the changes in nozzle configuration, air flow and pressure, grit size and flow rate. If the results from methods 1 and 2 are accordant, and that can indicate there is very little fluctuation in test conditions. As indicated in Fig. 6(b), the erosion rates from the three methods can be fully or partially consistent in most case.

In this work, the samples \#E-2A and \#E-2H show good correlation on the results between method 2 and 3; but the samples \#E-1A and $1 \mathrm{H}$ have major shift on the impinging angles for the high erosion rates derived from the method 2 and 3. Conclusively, the comparison chart in Fig. 6(b) proves the general consistency of the erosion test results from the three methods although the results are not fully correlated at some angles. The samples with increased erosion resistance are rated in the sequence of \#E-1H, \#E$1 \mathrm{~A}$, \#E-2A and \#E-2H, i.e., the composite phase TBCs 
performance better than the zirconate TBCs according to the overall erosion rates.

\section{Characterization of Surface Roughness}

The eroded surfaces were observed using optical and digital microscopes, and it was found that the eroded surfaces had different eroded textures on the TBCs along impinging direction ( $X$-direction) and normal direction to the grit stream ( $Y$-direction). To better describe the difference in the erosion textures, surface roughness Ra were measured along both $X$ - and $Y$-directions on the coating surfaces near to the maximum thickness loss areas. The results of normalized Ra ratio (i.e., Ra- $y / \operatorname{Ra}-x$ ) as a function of impact angle are given in Fig. 7. Two general trends are discovered: (1) the Ra- $y$ in $Y$-direction is larger than the Ra- $x$ in $X$-direction; (2) the normalized ratio of Ra- $y$ to Ra- $x$ clearly shows that the dependence of the ratio on the impinging angle. With increasing impact angle to $90^{\circ}$, the ratio is reduced close to 1:1, meaning the erosion texture become more uniform and less orientation related. The Ra results are able to characterize the TBCs in a quantative manner for their erosion behavior at microlevel. The Ra results also are related to coating microstructures, defects, and the coating response to the impact force locally within the footprint of erosion scar while the impact angle varies from low to high degree. The plot of blast footprint area or particle flux density with impact angle is given in Fig. 8. It is clearly indicated that particle flux density factor is increased while impact angle increases from low to high.

As APS sprayed TBCs have typically coating defects such as pores, and unique lamellar splat structures, all the microstructural features can contribute to the formation of different erosion textures on the eroded surfaces of the TBCs. Surely, the sample \#E-1A with multi-mode porosity

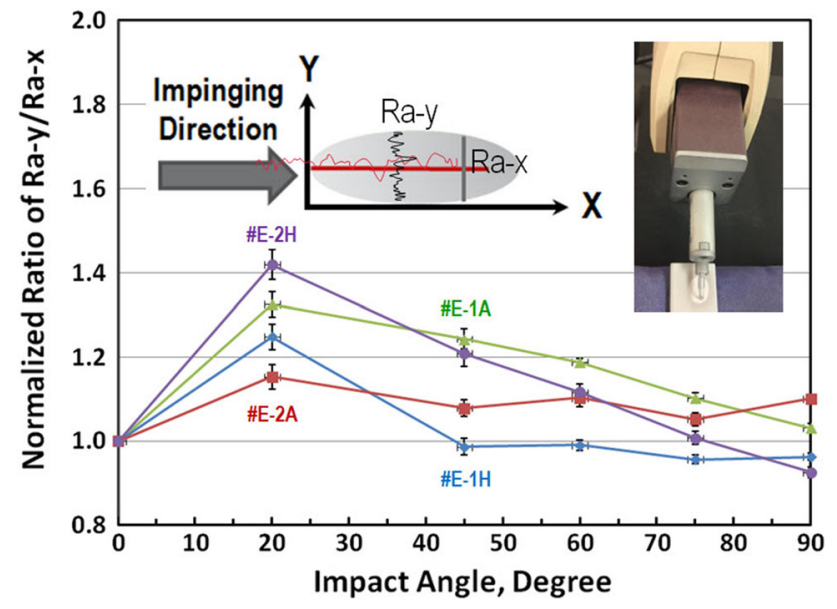

Fig. 7 Plot of surface roughness ratio measured on eroded TBCs along both $X$ - and $Y$-directions as a function of impact angle structure is influenced much by the change in impact angle relative to the sample \#E-2A with single-mode porosity structure. Inversely, after the aging treatment at $1300{ }^{\circ} \mathrm{C}$, the sample \#E-1H becomes less sensitive to the increase in impact angle than the sample \#E-2H. Therefore, the surface roughness $R a-x$ and Ra-y may be useful to characterize and differentiate the erosion behavior of various samples at a microscale level.

\section{Erosion Mechanism}

The solid particle erosion (SPE) behavior of a coating system can be affected by various factors, including the complex interaction between the erosion factors with the impacted surfaced (Ref 21-23). These factors include at least: (i) erodent particles: particle size, geometry and flux; (ii) impingement: velocity, angle and trajectory; and (iii) environment: temperature, humidity and gas chemistry; and (iv) impact surface: material, microstructure, surface texture and mechanical property. As to APS-formed TBC coatings, three different types of SPE were reported based on the observation of eroded coating areas (Ref 24, 25):

- Low erosion rate: Primary scars as principal observable feature on the erosion surface, when impacting particles produce mainly indentations on the surface and erosion takes place as material loss caused by successive impacts on deformed material.

- Moderate erosion rate: Occurrence of fractures around the impact area on the coating surface, when impact produces crack propagation along splat boundaries.

- High erosion rate: Tunnel formation on the surface, when the kinetic energy transferred from the solid particles to the coating target is high enough to connect pre-existing pores inside the TBC eroding clusters of several splats each time.

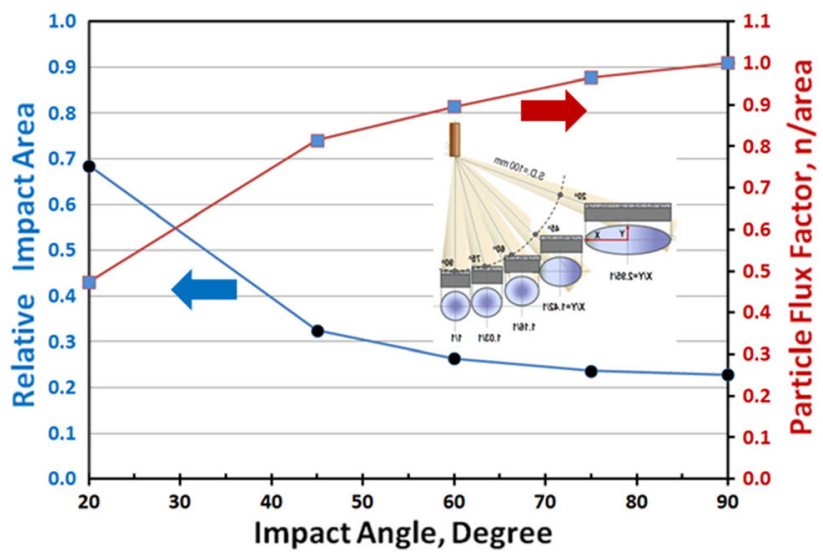

Fig. 8 Theoretical analysis on the factor of particle flux density as a function of impact angle 
The SEM surface topographs were taken on the eroded TBCs and are shown in Fig. 9. Several key features can be identified and characterized from the images: (i) low angle samples: Distinct eroded grooves or plunges exist along the impinging direction; (ii) medium angle samples: Both oriented grooves and craters are formed (iii) high angle samples: evenly roughened surfaces are created; and (iv) the TBC \#E-1A $\left(c+t^{\prime} \mathrm{ZrO}_{2}\right)$ is more surface texture-rich having a high surface roughness, and exhibits "ductile or tough" and "brittle" like behavior in compared to the TBC \#E-2A $\left(\mathrm{Gd}_{2} \mathrm{Zr}_{2} \mathrm{O}_{7}\right)$ with dominantly "brittle" behavior. This observation is consistent with the results of the surface Ra measurement in Fig. 7. The SEM images offer implications with respect to the surface eroded textures and erosion mechanisms for the two types of TBC coatings at different impact angles.

The intrinsic fracture toughness of a topcoat ceramic has decisive effect on erosion behavior. Therefore, the fracture toughness of the TBCs \#E-1A and \#E-2A was measured by Vickers micro-indentation method. Then, the fracture toughness was calculated from the indentation marks as shown in Fig. 10 using the proposed equation for Palmqvist cracks by Chiot (Ref 26), although some large cracks (i.e., radial-median cracking and intermediate cracking) also exist in the TBC \#E-2A. The values of the TBCs' fracture toughness $K_{\mathrm{Ic}}$ are about 1.19 and $0.72 \mathrm{MPa} \mathrm{m}^{1 / 2}$ for zirconia-based TBC \#E-1A and zirconate-based TBC \#E-2A, respectively, which are comparable to some reported data (Ref 27, 28). As illustrated in Fig. 1, for brittle mode there is a large erosion rate at a high impact angle, where the coating fracture takes place. Therefore, it can be explained that the TBC \#E-1A has much low erosion rate compared to the TBC \#E-2A due to its higher fracture toughness $K_{\text {Ic }}$. Additional aging at $1300{ }^{\circ} \mathrm{C}$ will promote coating sintering and sequentially reduce fracture toughness (Ref 29). Thus, the reduction in fracture toughness can explain the result that the TBC \#E-1H after aging treatment became worse to resist erosion damage. In view of all the results, it can be concluded that the combined mode of ductile/tough mode and brittle mode is more suitable to describe the erosive wear behavior of the TBCs, especially for the composite phase TBC samples at high impingement angles.

The erosion surface morphologies as shown in Fig. 9, indicate that the erosion took place initially and readily in the low density regions in the TBC samples. Our previous studies revealed that the coating porosity was reduced from current $13-15 \%$ to $8-10 \%$ if the plasma power was increased by $15-20 \%$. For the $c+t^{\prime}$ YSZ-TBC, the increase in coating density may increase its erosion resistance due to the reduction in weak connected area, mainly the porous clusters in the coating as shown in Fig. 4(b). However, the zirconate TBC may decrease its erosion resistance due to the loss of its fracture toughness $\mathrm{K}_{1 \mathrm{c}}$ as described by brittle-mode failure mechanism. The erosion results of the as-sprayed and sintered TBCs in Fig. 6 had supported the above analyses for the effect of coating density on the different erosion behaviors of the two TBC systems.
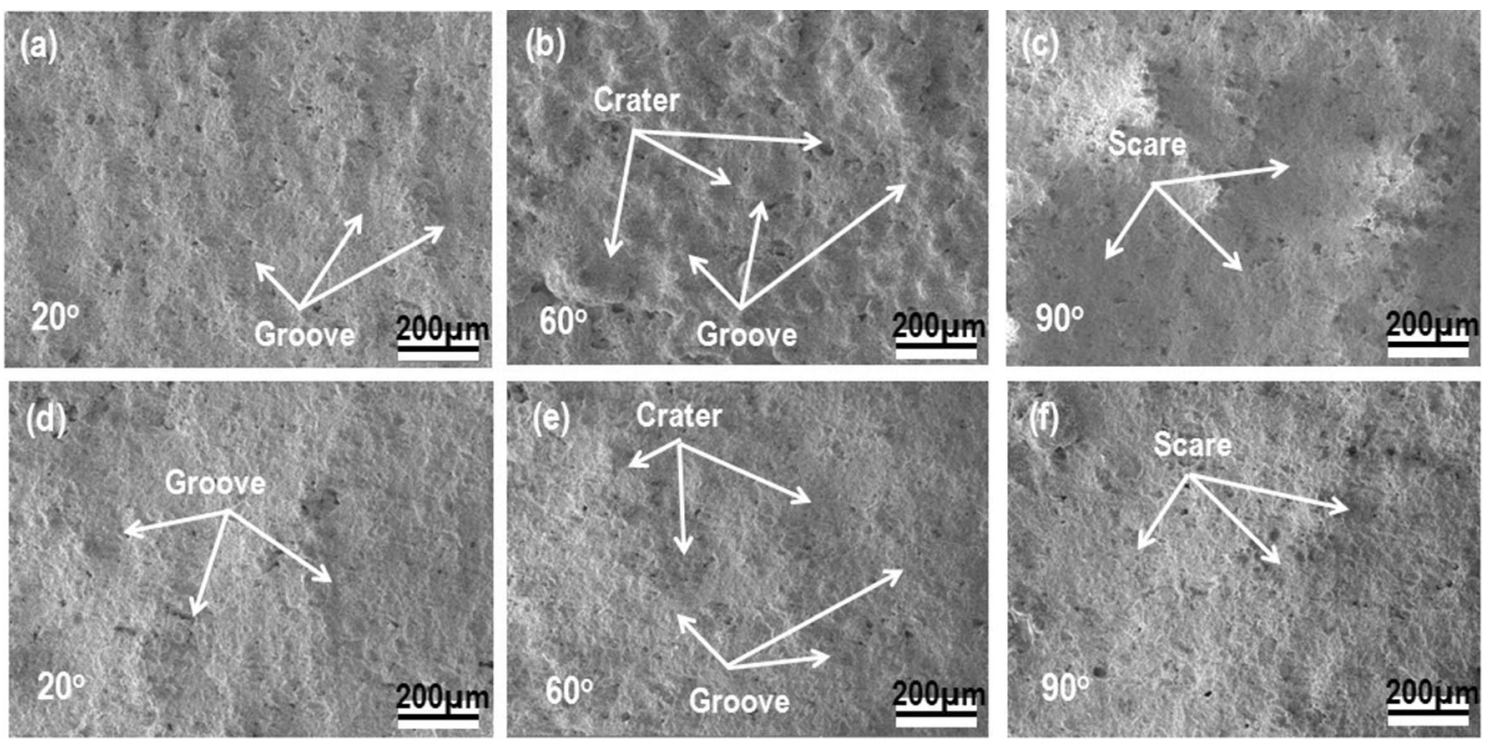

Fig. 9 SEM surface morphologies of the TBCs after SPE tests at different impinging angles. (a), (b), (c): TBC \#E-1A (c + t' zirconia); (d), (e), (f): $\mathrm{TBC} \# \mathrm{E}-2 \mathrm{~A}\left(\mathrm{Gd}_{2} \mathrm{Zr}_{2} \mathrm{O}_{7}\right.$ zirconate) 
Fig. 10 Typical Vickers microindentations taken under a load of $1000 \mathrm{~g}$ on (a) TBC sample \#E-1A and (b) TBC sample \#E$2 \mathrm{~A}$, respectively
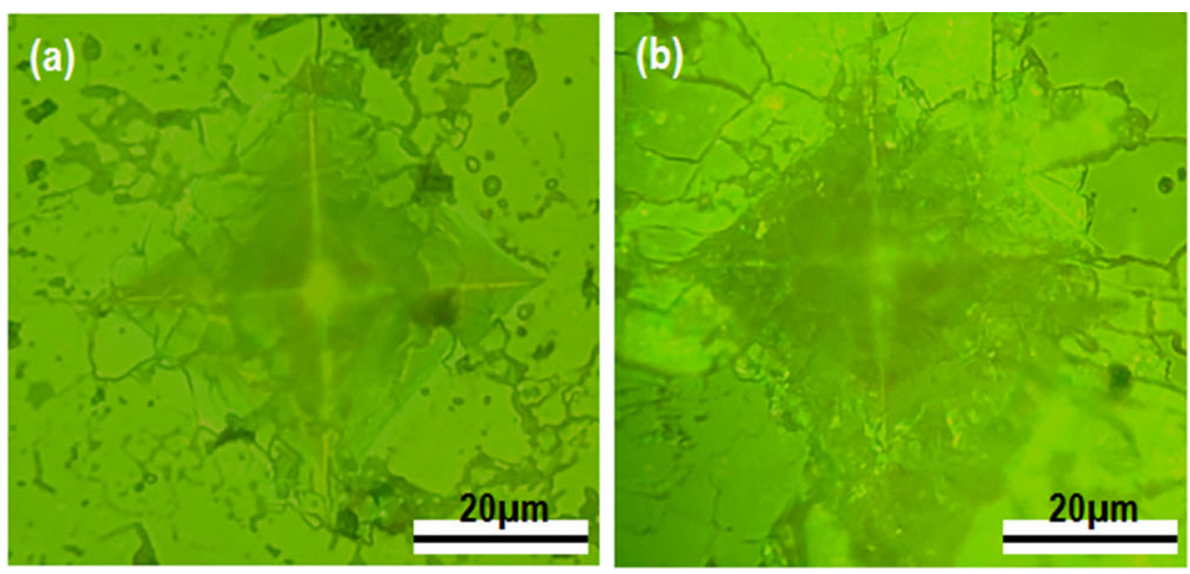

\section{Burner Rig Test}

\section{Coating Behavior}

The burner rig test (BRT) has been often performed for evaluating TBCs' thermal shock resistance and predicting their lifetime. A BRT setup using a simple gas nozzle is able to simulate the thermal cycling condition of rapid heating and cooling for limited cycle number. This type of economic BRT test excludes the effects of gas velocity on coating erosive impacting, and thermally grown oxide (TGO) on the increase of stress at the bond coat TBC interface (Ref 30). In some labs, high energy laser beam was utilized to introduce a high heat flux and a large thermal gradient in the TBC system, but not a speedy gas stream condition (Ref 31). Ideally, the BRT setup using a large fuel burner has the capability of providing both high heating and fast velocity to simulate an engine combustion environment, but not widely available and highly expensive to operate. The special BRT setup used in the present work provides an economic solution for high temperature and high-velocity BRT test in an economic way by utilizing a commercial available combustion flame torch comprising of a combustion chamber and a gas accelerating nozzle.

The coating behaviors of the TBC samples were continuously monitored during the BRT test by checking on coating surfaces. The coating failure was defined as $30 \%$ spallation of the total topcoat area. The plot of coating spallation \% with increasing cycle number is presented in Fig. 11. At 1000 cycles, the TBC \#B-1A $\left(\mathrm{c}+\mathrm{t}^{\prime} \mathrm{TBC}\right)$ has about $27 \%$ failure and the TBC \#B-2A ( $\mathrm{t}^{\prime}$ TBC) about $35 \%$ which is above the $30 \%$ threshold of TBC failure criterion. The TBC \#B-1A failed at about 1330 cycles. Between 1000 and 2000 cycles, the TBC \#B-1A has a lower spallation \% than the TBC \#B-2A, but both the TBCs exhibit a similar linear increase in the spallation \% against cycle \#. Based on our previous works, both the TBCs should survive for at

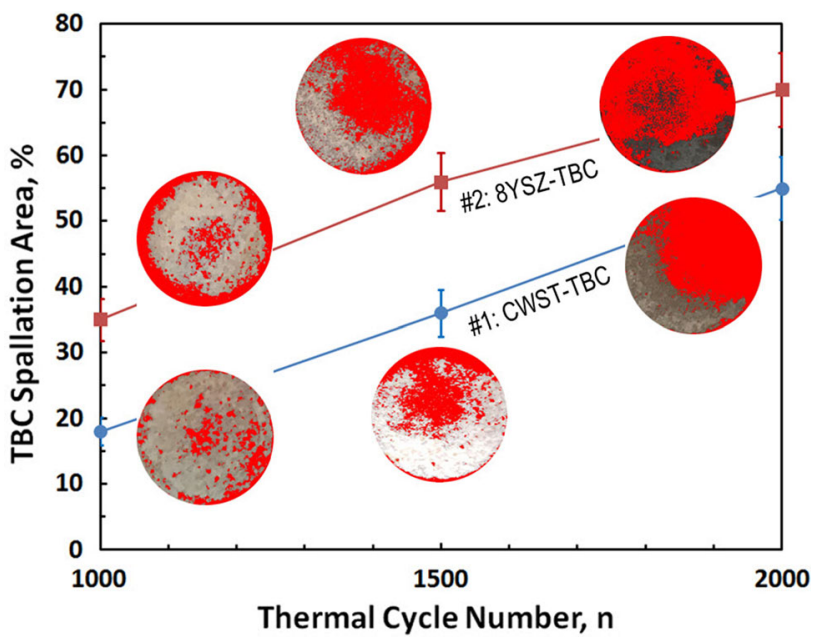

Fig. 11 Plot of percentage of TBC spallation area as a function of thermal cycle number. Coating failure is defined as $30 \%$ spallation area, and the image areas in red color indicate the TBC spallation areas analyzed by image processing method. \#1:CWST-TBC (\#B1A); \#2: 8YSZ-TBC (\#B-2A). Spalled areas are indicated in red (Color figure online)

least 2000 cycles in a simple BRT test without a high gas velocity. With the special BRT setup in current study, it is assumed that the severe coating damage and failure was attributed to the combined factors of thermal driven stress and erosive impact of high-velocity gas stream on the topcoat surfaces.

\section{Coating Examination}

The TBC samples during or after the BRT testing were examined on their surface conditions and microstructures. The spallation areas on those TBCs were identified by image analysis method, and are shown in red color in Fig. 11. At 1000 cycles, the spallation of the topcoat TBCs was located mainly around the edges and then started to 
initialize TBC loss at the central areas. Eventually, the spallation was propagated and enlarged from the edges into the main central areas. The microstructure analyses on the cross sections of the TBCs identified the locations of the coating failure within the TBCs. Before the completion of 1000 cycles, the topcoat failure located mainly within the topcoat or at the YSZ layer-topcoat interface. After 1000 cycles, the main failure migrated to the bond coat and topcoat interface. The surface photographs taken on the
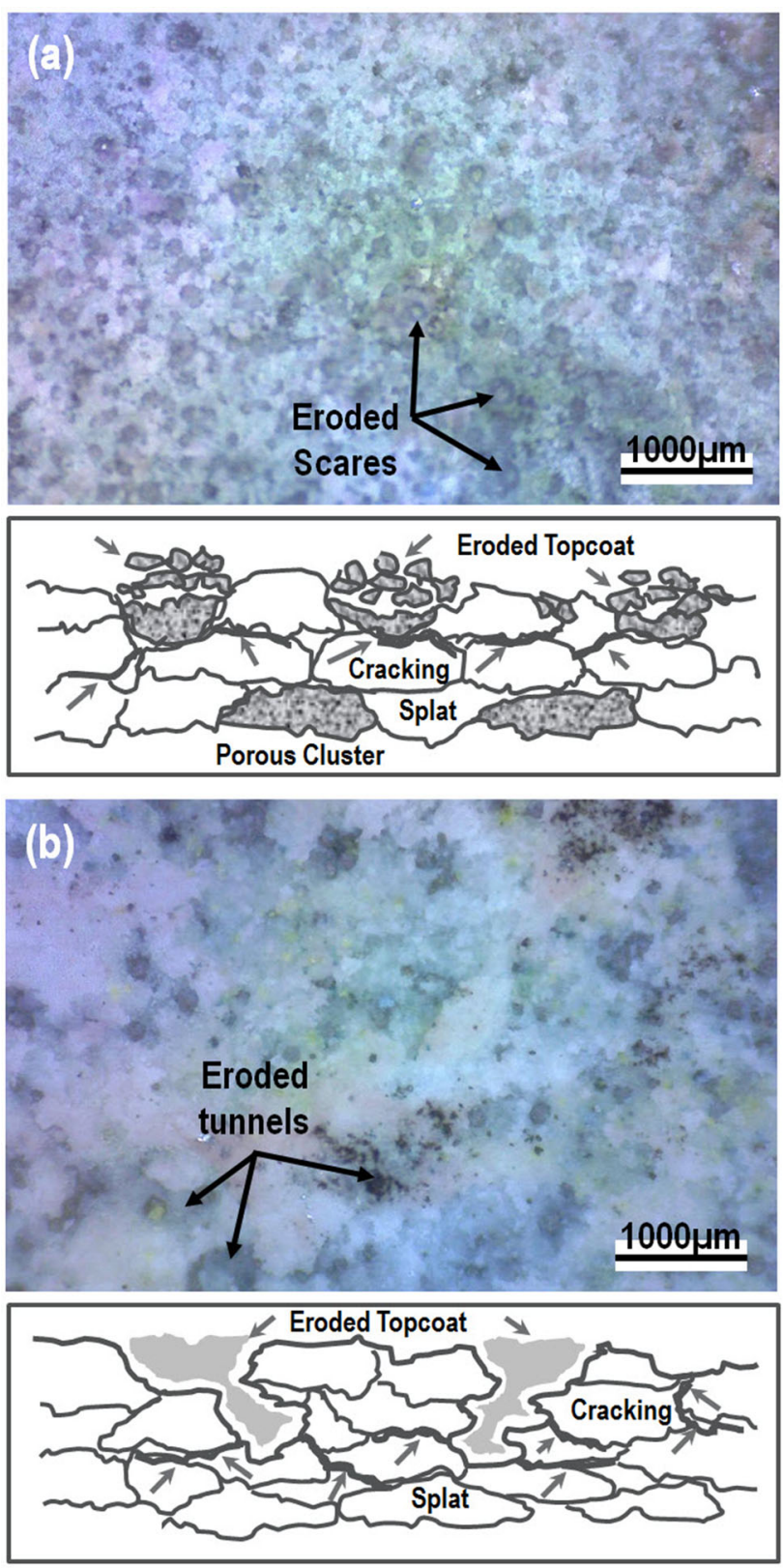

Fig. 12 Optical surface photographs and schematic failure modes of the TBCs after 2000 cycles of burner rig test. (a) Composite phase TBC \#B-1A and (b) 8YSZ-TBC \#B-2A remaining TBCs are presented in Fig. 12, indicating the uniqueness and differences in the TBC damage modes. The TBC \#B-1A $\left(c+t^{\prime}\right.$ phase) is cavitation-like with lots of localized coating loss and the TBC \#B-2A ( $\mathrm{t}^{\prime}$ phase) tunnel-like with deep hollow pockets down to the bond coat.

\section{BRT Failure Mode and Mechanism}

The TBC failure mechanisms under a variety of burner rig test conditions were investigated extensively. The possible TBC failure mechanisms were proposed based on the facts of the interface delamination due to thermal stress and or TGO induced stress, TBC sintering, phase transformation and erosion. With the special BRT setup and the experimental observation in present work, it is believed that the spallation of the TBCs was initialized on the edge areas due to highly concentrated thermal stress during the early cycling time, nominally less than 1000 cycles. This kind of TBC's edge spallation is often observed on disk-like specimens (Ref 7). With the progress of the thermal cycling, micro-cracking started to grow and propagate radically within the splats and laterally along the splat boundaries (Fig. 12). When the high-velocity gas stream impacted on the TBC surfaces, it could attack preferentially on the defective splats in the topcoats, and eroded the coating material selectively from the porous and cracked coating areas (Fig. 12). The TBC sample \#B-1A (c $+\mathrm{t}^{\prime}$ TBC) has multiple-mode porosity including porous clusters which are more prone to erosion loss as observed from the surface photograph in Fig. 12(a). In contrast, the TBC sample \#B-2A ( $\mathrm{t}^{\prime}$ TBC) has single-mode porosity and relative uniform and dense splats which are resistant to the localized erosion attack. However, it exhibited tunnel-like coating loss due to splats chipping caused by aggressive thermal stress and strong high-velocity gas impact.

In nature, the multiple-mode $\mathrm{TBC}$ should have more strain tolerance than the single-mode one under the thermal cycling condition, and thus demonstrated relatively low TBC spallation. The linear relation of coating loss with cycling number implies that the TBCs' damages and topcoat spallation was continuous and progressive with increasing cycles. In this case, the TBCs' behavior is quite different from those under solely thermal cycling. Under the combined effect of primary thermal cycling (cracking and splat delamination,...) and secondary high-velocity gas impact (impact fatigue, erosive material removal,...), no doubt the TBCs' failure mechanism was unique and the TBCs' degradation was more severe than a normal case in simple BRT testing. 


\section{Conclusions}

The present work aimed to test and characterize the advanced thermal barrier coating comprising of a composite phase ceramic topcoat by solid particle erosion (SPE) test and burner rig test (BRT) as a continuing effort for a durable TBC development. The experimental investigation was focused on the most important characteristics of SPE behaviors of the TBCs, including the variations of erosion damages with impingement angle and with the effect of high temperature sintering. The erosion mechanisms were discussed based on the topographic images and fracture toughness analyses of the eroded samples. In the BRT testing, the TBC's degradation and failure modes were identified and explained based on the joint factors of thermal stress and high-velocity gas impact. The main results are summarized as:

- The SPE results showed that the erosion rates of the TBCs tested strongly depended on the impingement angle, and the highest erosion rates existed in the high angle ranges from 60 to $90^{\circ}$. Three characterization methods had been employed to determine and compare the erosion rates which represent respective contents and interpretation of the erosion rates.

- The composite phase TBC demonstrated low erosion rates relative to the zirconate-based TBC. The further sintering at $1300{ }^{\circ} \mathrm{C}$ was beneficial for improving its erosion resistance mostly due to the reduction in coating porosity and the enhancement in the coating integrity at splat boundaries. Combined mode of ductile or tough and brittle modes had been utilized to elaborate the TBCs' erosion behavior and erosion mechanism.

- The burner rig test specially utilizing a high-elocity gas torch was proved to significantly accelerate the TBCs' deterioration and failure under the condition of rapid heating-cooling cycle and erosive impact of highvelocity gas stream. The increase in coating spallation area $\%$ followed a nearly linear relation with cycling number for both the zirconia and zirconate-based TBCs.

- Based on the examination on coating microstructure and surface morphology, the TBCs' damages became much severe and the failure mechanism was assumed as the interacted effect of thermally driven spallation (primary) and erosive mass loss (secondary) due to the impact of high-velocity gas stream.

Acknowledgments The authors gratefully acknowledge technical assistance and experimental support from Mr. David Reynolds, Mr. Wayne Sproul, Development and Production Engineering, CurtissWright Surface Technologies, East Windsor, CT; and Ms. Beth Eaton for 3D digital microscope analyses, IMR Test Labs, Curtiss-Wright, Lansing, NY.

\section{References}

1. Y. Tamarin, Protective Coatings for Turbine Blades, ASM International, Materials Park, 2002

2. X. Ma et al., Low Thermal Conductivity Thermal Barrier Coating Deposited by the Solution Plasma Spray Process, Surf. Coat. Technol., 2006, 201(7), p 4447-4452

3. S.M. Meier and D.K. Gupta, Evolution of Thermal Barrier Coatings in Gas Turbine Engine Applications, J. Eng. Gas Turbines Power, 1994, 116(1), p 250-257

4. X. Ma and P. Ruggiero, Practical Aspects of Suspension Plasma Spray for Thermal Barrier Coatings on Potential Gas Turbine Components, J. Therm. Spray Technol., 2018, 27(4), p 591-602

5. D.R. Clarke, M. Oechsner, and N.P. Padture, Thermal Barrier Coatings for More Efficient Gas-Turbine Engines, MRS Bull., 2012, 37(10), p 891-902

6. D.R. Clarke and C.G. Levi, Materials Design for the Next Generation Thermal Barrier Coatings, Ann. Rev. Mater. Res., 2003, 33, p 383-417

7. X. Ma, K. Rivellini, P. Ruggiero, and G. Wildridge, Toward Durable Thermal Barrier Coating with Composite Phases and Low Thermal Conductivity, J. Therm. Spray Technol., 2020, 29(3), p 423-432

8. X. Ma, et al., Unpublished Report (Curtiss-Wright Surface Technologies, East Windsor, CT, USA, 2019)

9. A. Hamed, W. Tabakoff, and R. Wenglarz, Erosion and Deposition in Turbomachinery, J. Propuls. Power, 2006, 22(2), p 350360

10. A.G. Davis, D.H. Boone, and A.V. Levy, Erosion of Ceramic Thermal Barrier Coatings, Wear, 1986, 110, p 101-116

11. C. Vorkötter, D.E. Mack, O. Guillon, and R. Vaßen, Superior Cyclic Life of Thermal Barrier Coatings with Advanced Bond Coats on Single-Crystal Superalloys, Surf. Coat. Technol., 2019, 361, p 150-158

12. I.M. Hutchings, Transitions, Threshold Effects and Erosion Maps, Key Eng. Mater., 1992, 71, p 75-92

13. X. Ma and P. Ruggiero, Characterization of Ultra-Smooth Hardface Coatings Applied by Advanced HVOF Process, in TSS symposium of Thermal Spray Characterization: Materials, Coatings and Process, April 11-12, Charleston, SC, USA (2017)

14. C.S. Ramachandran, V. Balasubramanian, and P.V. Ananthapadmanabhan, Erosion of Atmospheric Plasma Sprayed Rare Earth Oxide Coatings Under Air Suspended Corundum Particles, Ceram. Int., 2013, 39, p 649-672

15. S. Mahade, N. Curry, S. Björklund, N. Markocsan, P. Nylén, and R. Vaßen, Erosion Performance of Gadolinium Zirconate-Based Thermal Barrier Coatings Processed by Suspension Plasma Spray, J. Therm. Spray Technol., 2017, 26, p 108-115

16. S. Mahade, D. Zhou, N. Curry, N. Markocsan, P. Nylén, and R. Vaßen, Tailored Microstructures of Gadolinium Zirconate/YSZ Multi-layered Thermal Barrier Coatings Produced by Suspension Plasma Spray: Durability and Erosion Testing, J. Mater. Proc. Technol., 2019, 264, p 283-294

17. S. Mahade, C. Ruelle, N. Curry, J. Holmberg, S. Björklund, N. Markocsan, and P. Nylén, Understanding the Effect of Material Composition and Microstructural Design on the Erosion Behavior of Plasma Sprayed Thermal Barrier Coatings, Appl. Surf. Sci., 2019, 488, p 170-184

18. J. Lankford, Indentation Microfracture in the Palmqvist Crack Regime: Implications for Fracture Toughness Evaluation by the Indentation Method, J. Mater. Sci. Lett., 1982, 1, p 493-495

19. N.H. Faisal et al., An Improved Vickers Indentation Fracture Toughness Model to Assess the Quality of Thermally Sprayed Coatings, Eng. Fract. Mech., 2014, 128, p 189-204 
20. G.K. Beshish, C.W. Florey, F.J. Worzala, and W.J. Lenling, Fracture Toughness of Thermal Spray Ceramic Coatings Determined by the Indentation Technique, J. Therm. Spray Technol., 1993, 2, p 35-38

21. C.J. Li, G.J. Yang, and A. Ohmori, Relationship Between Particle Erosion and Lamellar Microstructure for Plasma-Sprayed Alumina Coating, Wear, 2006, 260, p 1166-1172

22. K.C. Goretta, J.I. Pena, V.M. Orera, N. Chen, D. Singh, and J.L. Routbort, Solid-Particle Erosion of Directionally Solidified $\mathrm{Al}_{2} \mathrm{O}_{3}-\mathrm{ZrO}_{2}\left(\mathrm{Y}_{2} \mathrm{O}_{3}\right)$ Eutectics, Wear, 2010, 268, p 571-578

23. J. Kitamura et al., Structural, Mechanical and Erosion Properties of Yttrium Oxide Coatings by Axial Suspension Plasma Spraying for Electronics Applications, J. Therm. Spray Technol., 2011, 20, p 170-185

24. S.B. Mishra, S. Prakash, and K. Chandra, Studies on Erosion Behaviour of Plasma Sprayed Coatings on a Ni-Based Superalloy, Wear, 2006, 260, p 422-432

25. H.E. Eaton and R.C. Novak, Particulate Erosion of PlasmaSprayed Porous Ceramics, Surf. Coat. Technol., 1987, 30, p 41-50

26. D. Dicot, G. Duarte, A. Tricoteaux, B. Jorgowski, A. Leriche, and J. Lasage, Vickers Indentation Fracture (VIF) Modelling to Analyze Multi-cracking Toughness of Titania, Alumina and Zirconia Plasma Sprayed Coatings, Mater. Sci. Eng., A, 2009, 527, p 65-76
27. C. Giolli, A. Scrivani, G. Rizzi, F. Borgioli, G. Bolelli, and L. Lusvarghi, Failure Mechanism for Thermal Fatigue of Thermal Barrier Coating Systems, J. Therm. Spray Technol., 1993, 18, p 223-230

28. V. Viswanathan, G. Dwivedi, and S. Sampath, Engineered Multilayer Thermal Barrier Coatings for Enhanced Durability and Functional Performance, J. Am. Ceram. Soc., 2014, 97(9), p 2770-2778

29. C.C. Li et al., Evolution of Mechanical Properties of Thermal Barrier Coatings Subjected to Thermal Exposure by Instrumented Indentation Testing, Ceram. Int., 2016, 42, p 10242-10250

30. H.D. Steffens and U. Fischer, Characterization and Thermal Shock Testing of Yttria-Stabilized Zirconia Coatings, Surf. Coat. Technol., 1987, 32(1-4), p 327-338

31. D. Zhu and R.A. Miller, Thermal Conductivity of Advanced Ceramic Thermal Barrier Coatings Determined by a Steady-State Laser Heat-Flux Approach, NASA Technical Report ARL-TR3262, NASA/TM-2004-213040, (2004), p 1-18.

Publisher's Note Springer Nature remains neutral with regard to jurisdictional claims in published maps and institutional affiliations. 